\title{
Two-phase pyrolysis modelling of wooden waste
}

\author{
C. Gheorghe, R. Dinu, C. Marculescu, A. Badea \& T. Apostol \\ Power Engineering Department, Polytechnic University of Bucharest, \\ Romania
}

\begin{abstract}
Pyrolysis technology has been demonstrated in recent researches as one of the most effective and environmentally friendly methods for solid wastes pretreatment and energy utilization. Pyrolysis is a process wherein organic materials are exposed to thermal treatment in the absence of an oxidizing agent, resulting in a solid (char), liquid (tar and bio-oil) and volatile gases $\left(\mathrm{CO}, \mathrm{CO}_{2}, \mathrm{CH}_{4}\right.$, and $\mathrm{H}_{2}$ ). A two phase (solid-gas) equilibrium model is proposed in this work in order to simulate the pyrolysis process of wooden biomass (spruce sawdust). The model is able to predict the amount of solid char, the yields and the chemical composition of pyrolysis gas for different process temperatures. In this case, process simulations were done for $600^{\circ} \mathrm{C}$ and $800^{\circ} \mathrm{C}$. Aiming the model validation, an experimental campaign was carried out using batch-scale pyrolysis reactor. The simulation results have shown a good agreement with the experimental once.
\end{abstract}

Keywords: biomass, pyrolysis, modelling.

\section{Introduction}

The energy conversion of the biomass is considered like a key action to attend the sustainable developpment objectivs of Kyoto Protocol, because it allows the reduction of the fossil fuel utilization, since the $\mathrm{CO}_{2}$ evacuated through the energy conversion process is compensate by the $\mathrm{CO}_{2}$ absorbed through the life cycle of the vegetals. Biomass, as part of the renewable energy, can achieve zero emission of $\mathrm{CO}_{2}$ and also can help the sustainable development [1]. Wood and other forms of biomass represent some of the main renewable solid energy sources available and provide the only source of liquid, gaseous and solid fuels [2]. 
Thermochemical biomass conversion includes a number of possible roots to produce useful fuels and chemicals from the biomass feedstock. Pyrolysis represents a process wich involves several reactions resulting in the releasing of mixtures of organic and inorganic gases, liquids from the particles in to the surrounding atmosphere [3] and solid fraction. Depending on the thermal environment and the final temperature, pyrolysis will yield mainly char at low temperatures, less than $450^{\circ} \mathrm{C}$, when the heating rate is quite slow, and mainly gases at high temperatures, arround $800^{\circ} \mathrm{C}$, with rapid heating rates [4].

In this study a two phase (solid-gas) equilibrium model is proposed in order to simulate the pyrolysis process of wooden biomass (spruce sawdust). The model is able to predict the amount of solid char, the yields and the chemical composition of pyrolysis gas for different process temperatures.

\section{Pyrolysis model}

\subsection{Model description}

Biomass pyrolysis process was also analyzed by authors through model simulations. In this sense, a Matlab code was written in order to reproduce the drying and devolatilization processes of the organic matter being considered. The model proposed in this study is a simplified one and works at equilibrium when the Gibbs free energy of the system has the minimum value (close to zero).

For reaching the equilibrium state, it has been assumed that the temperature and pressure remain constant and homogenous during each of two stages of the process. Also, the residence time of biomass within the system was considered to be long enough to allow devolatilization process to complete and consequently achieving an equilibrium state. The model can be considered having a biphasic character (solid-gas) due to its capacity estimating the gaseous and the solid fractions inside the products of reaction. The compositions and the yields of the gaseous species composing the pyrogas (mostly $\mathrm{CO}, \mathrm{H}_{2}, \mathrm{CO}_{2}$ and $\mathrm{CH}_{4}$ ), as well as solid carbon fraction, are estimated by a software tool named Cantera which is integrated within the model. The solver implemented in Cantera is a version of the Villars-Cruise-Smith (VCS) algorithm that finds the composition minimizing the total Gibbs free energy of an ideal mixture [5]. The applied procedure for solving the minimization problem is based on the stoichiometric formulation, in which the closed-system constraint is treated by means of the linearly independent stoichiometric equation (see eqn (1)) so as to result in an unconstrained minimization problem where $n^{0}$ is the initial composition vector, $v_{j}$ represents the stoichiometric coefficients vector and $\xi_{\mathrm{j}}$ are the extents of the reaction. The minimization procedure applied to the $G$ function, implies the computation of its partial derivatives with respect to the extents of the reactions (see eqn (2)) and gives the equilibrium condition (see eqn (3)).

$$
n=n^{0}+\sum_{j=1}^{R} v_{j} \xi_{j}
$$




$$
\begin{gathered}
\left(\frac{\partial G}{\partial \xi_{j}}\right)_{T, P, \xi}=\sum_{i=1}^{N}\left(\frac{\partial G}{\partial n i}\right)_{T, P, n}\left(\frac{\partial n_{i}}{\partial \xi_{j}}\right)_{\xi} \\
\sum_{i} v_{i j} \mu_{i}=0
\end{gathered}
$$

The model represents only a part (module) from a larger model simulating combustion process. A schematic diagram of the model is showed in fig. 1. As can be observed, the supplied raw material is first subject to a drying process which takes place at $105^{\circ} \mathrm{C}$. Here, the moisture inside the solid matrix of the fuel is released as water vapors. During pyrolysis process, the dried material entering in the pyrolysis zone of the reactor is further decomposed under temperature effect into a biphasic mixture (gas-solid). As pyrolysis char is composed mainly from carbon, the authors considered that it could be approximated only with graphite. The model can easily deal with different types of biomass because it takes into consideration the ultimate analysis of the fuel and its calorific value indicating a truthful description of energy and mass balance of the system.

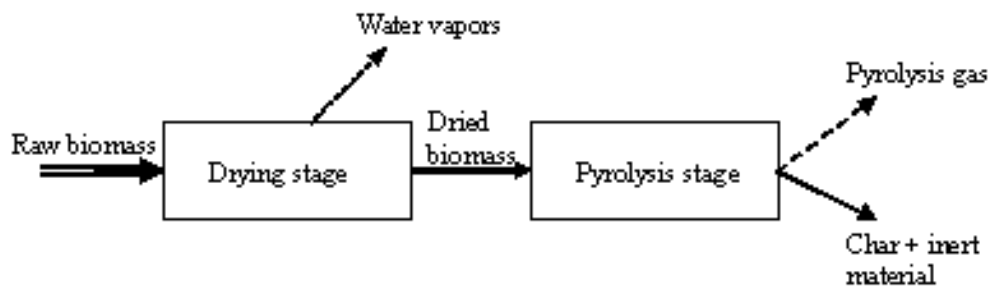

Figure 1: $\quad$ Structure of the modeled process.

\subsection{Model results}

In this work, the proposed model has been applied to spruce sawdust. The feedstock physical properties, proximate analysis and also ultimate analysis are presented in table 1 and are expresed in wet base. The lower heating value was estimated using empirical formulas like eqn (4) and eqn (5). The value finding in the next table was calculated with Milne's formula [6].

$$
\begin{aligned}
\mathrm{HHV}= & (0.341 \cdot \mathrm{C}+1.322 \cdot \mathrm{H}-0.12 \cdot \mathrm{O}-0.12 \cdot \mathrm{N}+ \\
& 0.0686 \cdot \mathrm{S}-0.0153 \cdot \mathrm{Ash}) \cdot\left(1-\frac{\mathrm{H}_{2} \mathrm{O}}{100}\right) \\
\mathrm{LHV}= & \mathrm{HHV}-2.442 \cdot\left(8.936 \cdot \frac{\mathrm{H}}{100} \cdot\left(1-\frac{\mathrm{H}_{2} \mathrm{O}}{100}\right)+\frac{\mathrm{H}_{2} \mathrm{O}}{100}\right)
\end{aligned}
$$


One of the main factors having major impact on pyrolysis process is temperature. Modifying this parameter during the process leads to: variations of products compositions and distributions; changes involving the heat amount to be supplied/liberated during the process and changes of the heating content of the pyrolysis products (gas, char).

The physical process of pyrolysis involves significant loss of fuel mass during the evolution of biomass to volatiles and char. The temperature influence on the pyrolysis products ratio can be observed from fig. 2. As expected, the char amount decreases with temperature due to the volatile releasing, reaching at $800^{\circ} \mathrm{C}$ about $22.4 \%$ from the reaction products. The figure also presents the calorific values for both categories of the products. The numerical values are related the raw biomass mass flux entered in the system.

Table 1: $\quad$ Biomass feedstock characteristics.

\begin{tabular}{lll}
\hline Physical properties: & \multicolumn{2}{l}{} \\
\hline Bulk density & $\mathrm{kg} / \mathrm{m}^{3}$ & 192 \\
\hline Proximate analysis (wet basis): & \multicolumn{2}{l}{} \\
\hline Ash content & $\%$ & 0.90 \\
Moisture & $\%$ & 8.25 \\
HHV & $\mathrm{MJ} / \mathrm{kg}$ & 16.89 \\
LHV & $\mathrm{MJ} / \mathrm{kg}$ & 15.62 \\
\hline Ultimate analysis (wet basis): & \multicolumn{2}{|}{} \\
\hline Carbon $(\mathrm{C})$ & $\%$ & 46.86 \\
Hydrogen $(\mathrm{H})$ & $\%$ & 5.36 \\
Nitrogen $(\mathrm{N})$ & $\%$ & 0.07 \\
Sulphur $(\mathrm{S})$ & $\%$ & 0.00 \\
Oxygen $(\mathrm{O} *)$ & $\%$ & 38.56 \\
\hline
\end{tabular}

(*) Measured by difference.

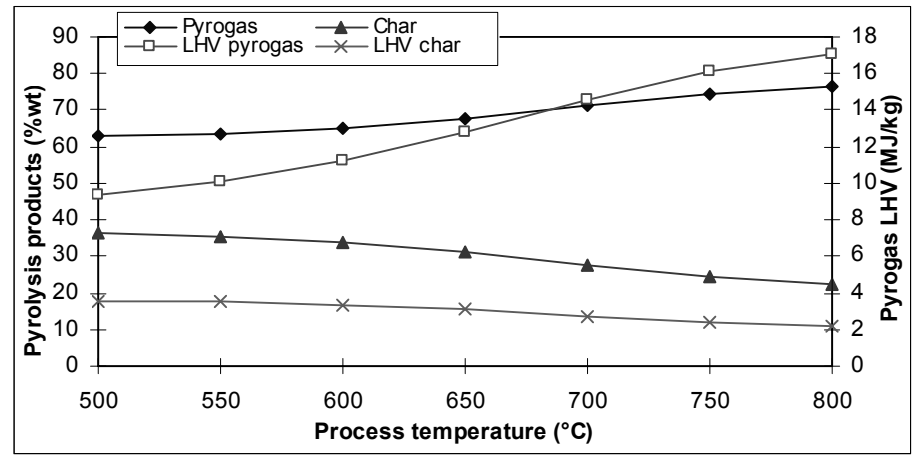

Figure 2: $\quad$ Pyrolysis products variation and their LHV. 
A variation of the pyrogas species with temperature can be observed in fig. 3 . As can be seen, the temperature strongly influences the distribution and the yields of the pyrogas species. The grater the temperature, the grater the $\mathrm{CO}$ and $\mathrm{H}_{2}$ concentrations and the lower $\mathrm{CH}_{4}$ content in the pyrogas is.

The $\mathrm{C}+\mathrm{CO}_{2} \rightarrow 2 \mathrm{CO}$ reaction shows that the process temperature also influences $\mathrm{CO}$ formation. The endothermic reaction between solid carbon and $\mathrm{H}_{2}$ to produce $\mathrm{CH}_{4}$ is not favoured by increasing temperature [7].

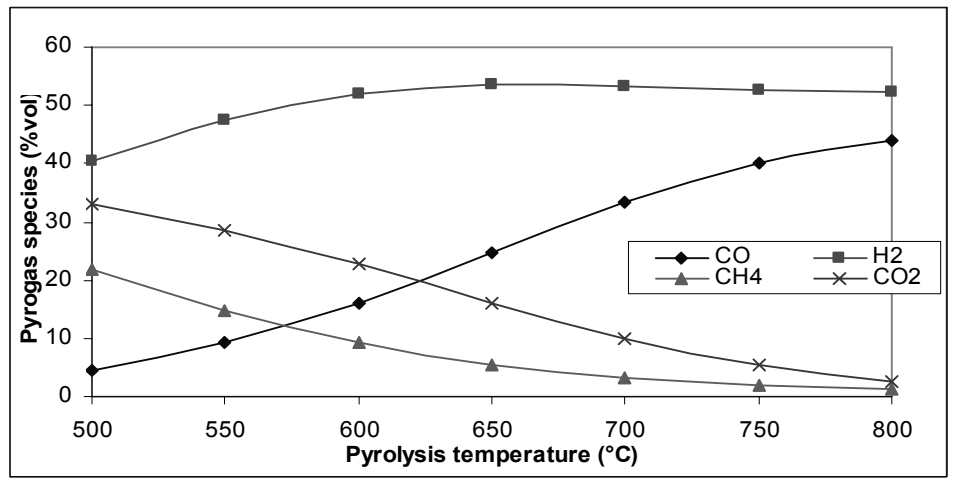

Figure 3: $\quad$ Main pyrogas species.

\section{Experimental}

\subsection{Experimental facility}

The installation used for this study is a bench-scale reactor made in the Power Engineering Department of Politechnical University of Bucharest based on an existing Nabertherm platform presented in fig. 4. The external electrically heated reactor is used for discontinuous treatment applied to solid materials. The reactor consists in an external heated tube within the inner diameter of $56 \mathrm{~mm}$ and 1200 $\mathrm{mm}$ long made of refractory alloy. The active zone, heated one, is about 750

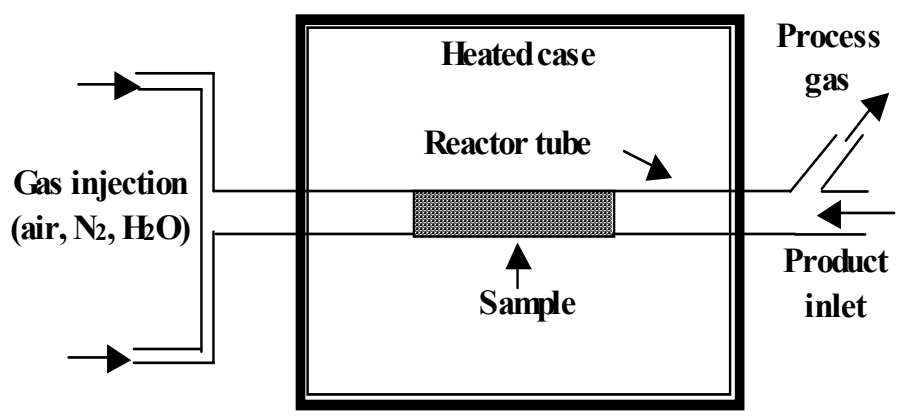

Figure 4: Functional scheme of the bench scale tubular reactor. 
$\mathrm{mm}$. The available volume for sample treatment is about $800 \mathrm{~cm}^{3}$ provided by a parallelepiped sample holder $1000 \mathrm{~mm}$ long. The sample holder is introduced coaxial from the free end of the reactor and sealed inside with a steel cap. At this end a septum insures the process gas sampling for analysis. A regulator valve controls the pressure inside the reactor.

At the other end the tube reactor has two gas inlets for gas injection and flow regulators. Therefore different experimental conditions can be reproduced: combustion with air or oxygen, pyrolysis with nitrogen or gasification with steam/air. This device accepts quantities up to 100 grams of solid products. The operating temperatures are in the range of $25-1200^{\circ} \mathrm{C}$. The heating rate can be set for a maximum of $30^{\circ} \mathrm{C} / \mathrm{min}$ by a temperature controller.

\subsection{Experimental results}

The pyrolysis experiments were performed using spruce sawdust as feedstock material. The fuel's proximate and the ultimate analysis were presented in section 2.2 (see table1). The experiments have been performed in case of the pyrolysis at atmospheric pressure and for the process temperatures equal with $600^{\circ} \mathrm{C}$ and $800^{\circ} \mathrm{C}$ for $300 \mathrm{~g}$ of material/probe. During of measurements nitrogen was continuously purged in the reactor zone. The flow rate of nitrogen was around $0.6 \mathrm{l} / \mathrm{min}$. A Shimadzu gas chromatograph (GC) was utilised to measure the fuel gas composition. The following gas components of the dry fuel gas were measured: $\mathrm{H}_{2}, \mathrm{CO}, \mathrm{CO}_{2}, \mathrm{CH}_{4}$ and hydrocarbons $\left(\mathrm{C}_{\mathrm{x}} \mathrm{H}_{\mathrm{y}}\right)$.

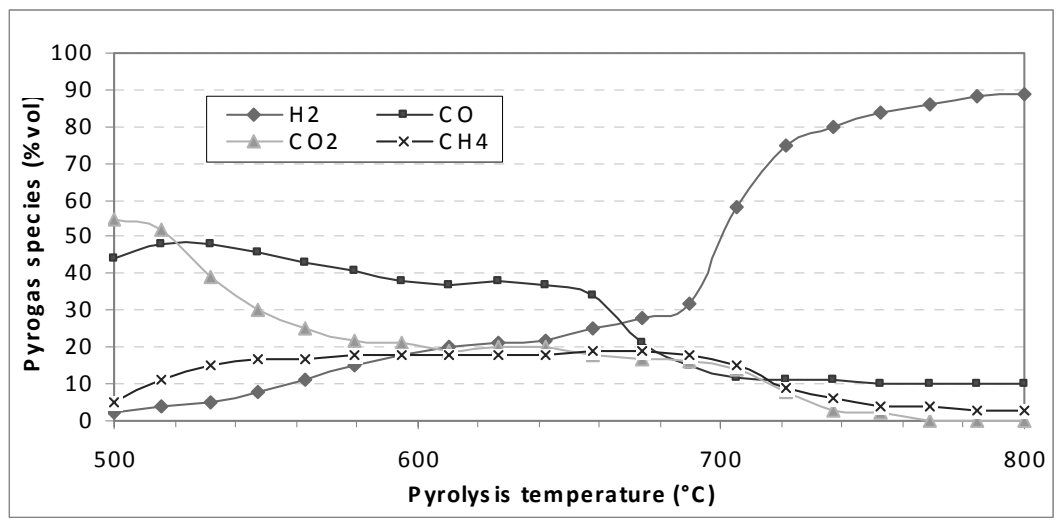

Figure 5: $\quad$ Pyrogas main species variation for $800^{\circ} \mathrm{C}$ maximum process temperature.

Figure 5 shows the variation of pyrogas species composition as function of process temperature. The conversion process of biomass starts with high production of $\mathrm{CO}_{2}$ that decrease with temperature in the same time the production of $\mathrm{CO}$ is favored until about $650^{\circ} \mathrm{C}$ due to the endothermic Boudouard reaction $\left(\mathrm{C}+\mathrm{CO}_{2} \rightarrow 2 \mathrm{CO}\right)$. After this temperature, both chemical 
compounds reach a plateau zone. The methane production is encouraged between $550^{\circ} \mathrm{C}$ and $700^{\circ} \mathrm{C}$. The $\mathrm{H}_{2}$ production curve can be divided in two zones. In the first one $\left(500-700^{\circ} \mathrm{C}\right)$, the $\mathrm{H}_{2}$ production is rate limited while in the second zone, it increases very fast due to the possible cracking of the larger molecules bonds and to the possible gasification conditions appearance.

The char yield decreases as the temperature increases. table 2 shows the amount of char for two pyrolysis temperatures $\left(600^{\circ} \mathrm{C}\right.$ and $\left.800^{\circ} \mathrm{C}\right)$. The second and the third colon shows values of the cahar amount obtained during experiments while the last column shows the model estimated values. Can be said that the calculated values are in good agreement with the experimental onces.

The differences between the experimental measured values (see table 3 ) come from installation type and products flow direction (co-current, counter-current). For co-current flow conditions, in the last section of reactor, vapour-gasification conditions are present due to process temperature $\left(800^{\circ} \mathrm{C}\right)$ and water vapours from product matrix. That explains the differences in $\mathrm{CO}$ and $\mathrm{CO}_{2}$ mean values.

Table 2: $\quad$ Char products mass fraction.

\begin{tabular}{llll}
\hline $\begin{array}{l}\text { Process } \\
\text { temperature }\end{array}$ & $\begin{array}{l}\text { Measured } \\
\text { values }\end{array}$ & $\begin{array}{l}\text { Measured values } \\
(*)\end{array}$ & $\begin{array}{l}\text { Estimated } \\
\text { values } \\
{[\% \mathrm{wt}]}\end{array}$ \\
{$\left[{ }^{\circ} \mathrm{C}\right]$} & {$[\% \mathrm{wt}]$} & {$[\% \mathrm{wt}]$} & 33.9 \\
\hline $600^{\circ} \mathrm{C}$ & 26.8 & 30.7 & 3.7 \\
$800^{\circ} \mathrm{C}$ & 21.6 & 22.5 & 22.4 \\
\hline
\end{tabular}

*Reference [8].

Table 3: $\quad$ Pyrogas composition mean values corresponding to a maximum temperature of $800^{\circ} \mathrm{C}$.

\begin{tabular}{lllll}
\hline $\begin{array}{l}\text { Gas species } \\
{[\% \text { vol }]}\end{array}$ & $\begin{array}{l}\text { Mean } \\
\text { values } \\
{[\% \text { mol] }}\end{array}$ & $\begin{array}{l}\text { Mean measured } \\
\text { values } \\
{[\% \text { vol] }(*)}\end{array}$ & $\begin{array}{l}\text { Mean calculated } \\
\text { values } \\
{[\% \text { vol] }}\end{array}$ \\
\hline $\mathrm{H}_{2}$ & 42.7 & 40.5 & 49.9 \\
$\mathrm{CO}$ & 24.6 & 14.1 & 16.1 \\
$\mathrm{CO}_{2}$ & 12.2 & 30.4 & 20.6 \\
$\mathrm{Hydrocarbons}$ & 20.5 & 15.0 & 13.3 \\
\hline
\end{tabular}

* Reference [9].

\section{Conclusions}

In the present work the performances of a simple pyrolysis analysis tool, capable to predict the yields of the reaction products have been verified. The model represents the pyrolysis process module within a thermodynamic analysis of biomass combustion process based on a multi-stage model that works at equilibrium by minimizing the Gibbs free energy. The model has been utilized to 
simulate the drying and pyrolysis stages and to evaluate the distribution and the composition of the pyrolysis biphasic products.

The reaction temperature is considered to be the driving parameter of the whole pyrolysis process because it influences directly the thermal state of the process and thereby the final products composition. This was confirmed from the results obtained both by experiments and model.

The results of the equilibrium model for the spruce sawdust pyrolysis were in general in the range of measured results (i.e. char, $\mathrm{H}_{2}$ ). The amount of $\mathrm{CO}$ and $\mathrm{CO}_{2}$ modelled were slightly underestimated respectively overestimated comparative to the experimental values. These differences may come from installation type and products flow direction in the last section of the reactor where the vapour-gasification conditions probably appear due to the process temperature.

\section{References}

[1] Wu, C., Ma, L., Modern Utilization Technology of Biomass Energy, Chemistry Industry Press, pp. 1-11, Beijing

[2] Bridgwater, A.V., Meier, D., Radlein, D., An overview of fast pyrolysis of biomass, Organic Geochemistry 30, pp. 1479-1493 (1999)

[3] de Souza-Santos, M. L., Solid Fuels Combustion and Gasification Modeling, Simulation, and Equipment Operation, Ed. Marcel Dekker Inc., U.S.A., pp. 28-29 (2004)

[4] Overend, R.P., Renewable Energy Sources Charged with Energy from the Sun and Originated from Earth-Moon Interaction - Thermochemical Conversion of Biomass, National Renewable Energy Laboratory, Golden, Colorado, USA

[5] http://sourceforge.net/projects/cantera

[6] http://www.ecn.nl/phylls

[7] Hossain, M.M., Développment d'un nouveau type de gazogène à charbon végétal, Thèse, Université Pierre et Marie-Curie, Paris-6 (1985)

[8] Demirbas, A., Effect of Temperature on Pyrolysis Products from Biomass, Energy Sources, Part A: Recovery, Utilization, and Environmental Effects 29 ,pp. 329-336(2007)

[9] Baggio, P., Baratieri, M., Grigiante, M., Tosi, P., Biomass Gasification Process: Experimental Analysis and Two-Phase Equilibrium Modeling, $15^{\text {th }}$ European Biomass Conference \& Exhibition, Berlin, pp 834-843 (2007) 